\title{
Product-Service Sustainability Assessment in Virtual Manufacturing Enterprises
}

\author{
Margherita Peruzzini, Michele Germani, and Eugenia Marilungo \\ Università Politecnica delle Marche \\ via Brecce Bianche 12, 60131 Ancona (AN), Italy \\ \{m.peruzzini,m.germani, e.marilungo\} @univpm.it
}

\begin{abstract}
New directions in modern industry are creating distributed virtual enterprises and pushing companies towards service-enhanced products. Both trends converge when a Virtual Manufacturing Enterprise (VME) is created to provide product-service solutions. At the same time, sustainability is a crucial aspect for industrial networks. This paper proposes a methodology to assess the sustainability of Product-Service Systems (PSS) in a VME by modelling an integrated lifecycle, defining impact categories and KPIs, and evaluating all the partners' contributions. The method allows easily comparing PSS design alternatives to each other or with traditional products. The industrial case study is represented by a "washing as a service" solution proposed by a worldwide VME. Sustainability assessment is useful to highlight the service benefits as well as the critical phases, and to support VME decision-making.
\end{abstract}

Keywords: Service-enhanced products, Sustainable manufacturing networks, Product-Service Systems (PSS), Virtual Manufacturing Enterprise (VME), Sustainability.

\section{$1 \quad$ Introduction}

Nowadays manufacturing enterprises are involved in the transition from products to Product-Service Systems (PSS). This trend mainly consists of adding a wide range of services to increase the value perceived by the customers and better satisfy their needs over time [1]. Furthermore, service-enhanced products (e.g. maintenance, user training, retrofitting and product monitoring, etc.) can significantly influence product performances and improve PSS sustainability.

Anyhow creating a PSS implies two main important changes in company's processes: firstly, the traditional product lifecycle has to be enhanced by including also service management; secondly, the product-oriented company model must be extended to realize a service-oriented ecosystem [2]. Indeed, interrelations between products and non-physical services are complex to model and they require managing new relationships between different stakeholders by creating a Virtual Manufacturing Enterprise (VME). Managing such complex scenario can add value with low impact and realize more sustainable processes thanks to the exploitation of the whole ecosystem capabilities [3]. In this context, sustainability assessment can be useful to 
understand the benefits connected to PSS and the effective advantages in respect with traditional products and to support strategic decision-making in the VME. However, a reliable analysis can be achieved only by considering a new integrated lifecycle and the ecosystem as a whole.

The research proposes a methodology to carry out a holistic sustainability assessment of PSS in complex manufacturing ecosystems. It defines an integrated lifecycle and, for each phase, indicates the sustainability objectives (economic, ecological or social) to be achieved. Objectives are than concretized by a set of KPIs that can be measured by specific assessment techniques (i.e. LifeCycle Assessment LCA, LifeCycle Cost Assessment LCCA, Social LifeCycle Assessment SLCA) and normalized to obtain a unique Sustainability Assessment value (SA). Finally, the impacts are mapped in the VME by eliciting the specific contributions of the ecosystem partners. It can be adopted until the preliminary design stages to envisage the global impacts of different PSS design solutions and highlight the most critical phases and objectives in danger. The methodology is validated by an industrial case study focusing on the "EasyWash service", which offers a set of washing services instead of the traditional product (washing machine). Analyses allow investigating the benefits of he proposed PSS and understanding how to optimize the sustainability within the VME.

\section{Product-Service Sustainability Assessment}

A product-service consists of a mix of tangible core products and intangible services designed and combined to increase the value for customers [4]. Value creation can be provided through an extended business network involving different stakeholders, which concur to create the services. The term PSS includes the product-service itself, the enterprise network and the infrastructures needed [5].

Services can provide great advantages on sustainability according to all the three dimensions considered by the modern sustainability thinking: environment, economics and social wellbeing [6]. From the economic viewpoint, services create new market potentials and higher profit margins, and can contribute to higher productivity by means of reduced investment costs along the lifetime as well as reduced operating costs for the final users. From an ecological viewpoint, productservices can be more efficient thanks to a more conscious product usage, an increased resource productivity and a close loop-chain manufacturing as reported by some examples [7-8]. Finally, services are able to support the building up and securing of knowledge intensive jobs, and can contribute to a more geographically balanced wellbeing distribution [9].

In industry, product sustainability can be achieved by adopting lifecycle design approaches: they allow quantifying product impacts and providing tangible commercial values in terms of efficiency and costs [10]. They are based on the definition of key parameters and indicators as metrics to assess the lifecycle performance (e.g. functionality, manufacturability, serviceability, environmental impact) and support comparative analysis [11]. Some techniques representing the basis for lifecycle assessment analysis are LifeCycle Assessment (LCA) [12] and LifeCycle Costing (LCC) [13]. Recently, also the social dimension has been included 
by the so-called Social LifeCycle Assessment (SLCA) [14]. However, the application of lifecycle techniques generally refers to physical products and adopts the single company perspectives. Only few recent studies try to apply lifecycle methods for PSS assessment [3]. However, the ecosystem has never been considered nor the partners' impact investigated.

Creating product-services implies the involvement of organizations, public bodies, tertiary service providers and customers to create a new business framework that is organized to support both product and service lifecycles. It entails moving from the traditional concept of virtual enterprise to the new idea of VME: a virtual enterprise is an aggregation of several business partners sharing costs and resources for the purpose of producing a product [15], while a VME focuses on PSS and contemporarily involves manufacturing agents (internal or external) producing and supplying products and services, and sales agents negotiating with customer agents [16]. In this context, considering the sustainability of PSS in the VME by understanding the impacts on the three sustainability dimensions can be particularly interesting and represents a novelty in research and in industry.

\section{Product-Service Sustainability Assessment in the VME}

A product-service sustainability assessment in complex ecosystems can be achieved by a structured methodology that considers the different aspects of sustainability and extends the analysis to the involved VME. The main novelties are:

- the approach, as it considers an integrated lifecycle considering both product and service phases and additional stages about the product-service system management;

- the service evaluation, as it applies sustainability analysis techniques not only for product abut also for service assessment;

- the VME perspective, as it analyses the involved partners of the virtual enterprise and their roles, and it determines the specific impact for each of them.

The proposed method consists of the following steps (Fig.1):

1. Definition of an integrated Product-Service Lifecycle: it considers all the activities related to product and service realization, from PSS ideation and design until PSS disposal. Lifecycle modelling considers the product as well as the technological infrastructure and the services;

2. Identification of the sustainability objectives: it includes environmental, economic and social objectives for each lifecycle phase;

3. Definition of the relevant KPIs: for each objective, a set of key indicators is defined according to sustainability purposes and manufacturing serviceenhanced products;

4. Definition of reliable measuring techniques to assess the KPIs: a combination of suitable lifecycle design techniques is defined to assess PSS sustainability. In particular, LCA focusing on environmental resources and ecosystem, LCCA estimating the lifecycle total costs, and SLCA estimating impacts on human resources and human health; 
5. Ecosystem analysis and correlation between the lifecycle phases and the VME partners involved: objectives are related to a specific ecosystem actor in order to separate the sustainability impacts;

6. Measurement of the global sustainability assessment for the VME: for each relevant lifecycle phase and for each identified ecosystem actor, KPIs are separately measured by combining the selected techniques and normalizing the single indexes to have a unique sustainability assessment value (SA), as expressed by Eq. (1):

$$
L C A+L C C A+S L C A=S A
$$

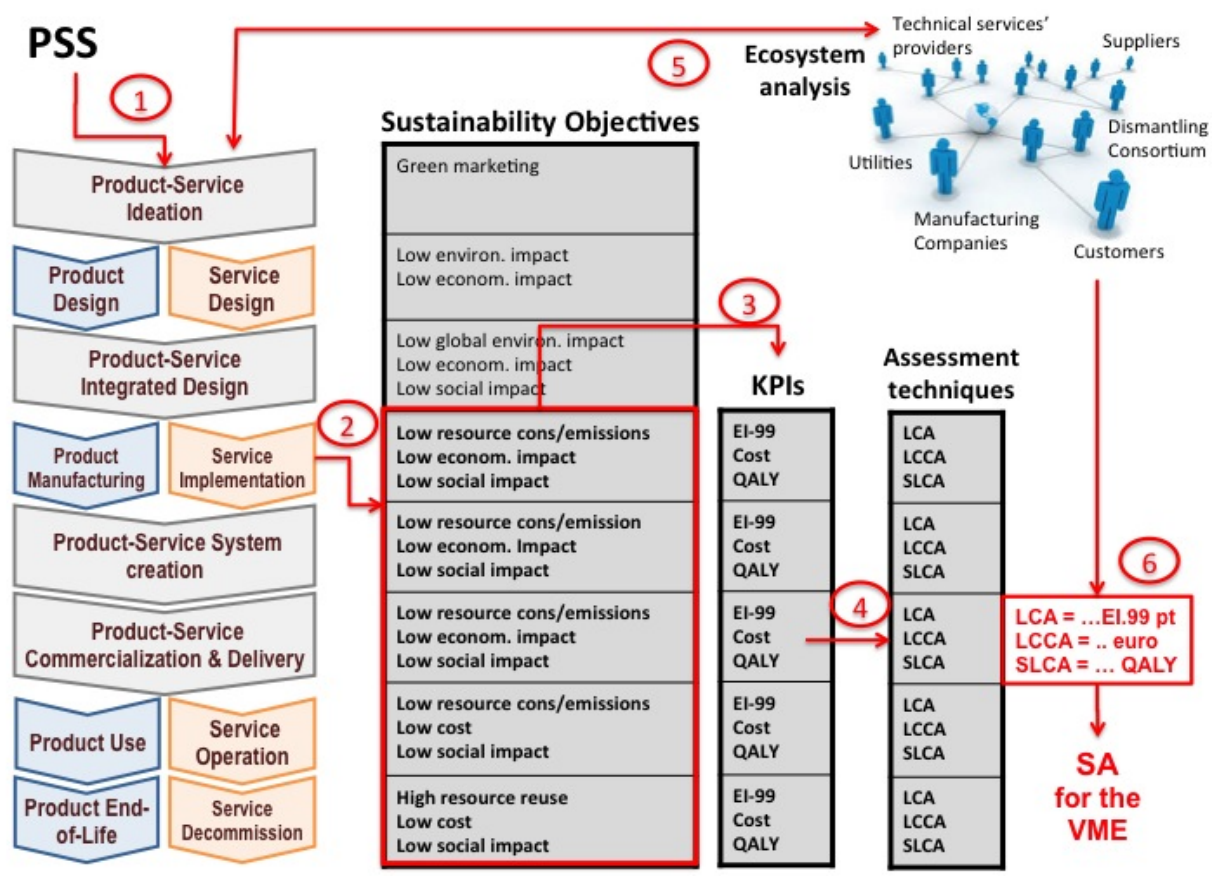

Fig. 1. Methodology steps for Product-Service sustainability assessment in the VME

Sustainability assessment focuses on the operative phases, from the end of the design stage until the end-of-life. Indeed, ideation and design slightly affect sustainability and in a similar way for different solutions, so these phases are neglected for the research purposes.

The lifecycle analysis considers all significant data referring to the analysed phases for product (manufacturing, use, end-of-life), service (implementation, operation, decommission) and product-service system (creation, commercialization and delivery). Environmental impact is measured by Eco-Indicator99 (EI-99) considering Ecosystem Quality impact and Resources consumption. The unit of measurement is EI-99 point $(\mathrm{Pt})$. Economic impact relates to the material use and transformation cost (MegaJoule or euro/dollars) as well as the lifecycle resources consumption cost (MegaJoule) within the entire ecosystem. It adopts the Equivalent Annual Cash Flow 
technique (EA) to transform a generic cash flow distribution into an equivalent annual distribution by cost actualization according to Eq. (2):

$$
E A=P \frac{(i+1)^{n} * i}{(i+1)^{n}-1}
$$

where $n$ is the lifetime years' number, $i$ is the generic discount rate (e.g. 3\%), and $P$ is the value during the entire lifetime. The impact is expressed in Euro. Finally, social impact considers separately Human Health contributions according to EI-99 methodology as before. Impact is expressed into QALYs (Quality Adjusted Life Years). Such values can be calculated by LCA and LCCA software tools (i.e. SimaPro, Gabi). For each lifecycle phase LCA, LCCA and SLCA are coupled to obtain a unique sustainability index via proper data normalization. The environmental impact, originally expressed in EI-99 pt., can be translated into PDFm ${ }^{2}$ yr (Potentially Disappeared Fraction of species per square meter per year) and MJ (MegaJoule), and normalized by Eq. (3) and Eq. (4). The social impact, originally expressed in QALYs, can be multiplied for the estimate cost for year according to recent European data, be Eq. (5).

$$
\begin{aligned}
& P t=P D F m^{2} y r \text { and }\left(P D F m^{2} y r\right) * 1,4=\text { euro } \\
& P t=M J \text { and } M J * \frac{0,00411}{\text { lifetime }}=\text { euro } \\
& 1 Q A L Y s * 74.000=\text { euro }
\end{aligned}
$$

The three monetary values (in euro) are summed to obtain a unique SA value.

Such a method has two main implications to practices: it is general and can be carried out for assessing PSS as well as product since the lifecycle will be simplified by considering only product-oriented activities. It has three main advantages: providing a global overview according to a lifecycle approach; anticipating the sustainability impact analysis and supporting early decision-making as it can be adopted until the preliminary design stage; and carrying out comparative analyses since it well addresses product-services as well as traditional products. Such a method applies a metric-based approach, which can be usefully adopted in design to compare investigate specific aspects of VMEs (e.g. collaboration, knowledge management, etc.) [17-18].

\section{The Product-Service Case Study}

The case study has been realized in collaboration with Indesit Company, a world leader in household appliances. The company actually designs, produces and sells product and leads a vertical supply-chain. The case study aims to investigate the idea of proposing no more products but services for Indesit Company and its ecosystem. In particular, it focuses on washing machines and analyses the so-called "EasyWash service": it provides the washing machine rent for free, a supply agreement comprising the washing energy and the detergent supply by paying an annual fee, and 
a web/mobile application for machine monitoring and customer training. The "EasyWash service" aims at creating a direct relationship with the customers by facilitating the product use in two ways: providing a turnkey solution able to make the machine ready to use and educating the customers in a correct use and energy/cost saving practices.

Such service requires realizing a PSS that comprehends the product, the service and the infrastructure. The case study product is a new prototype derived for the commercial Hotpoint Aqualtis model, the service is realize by an advanced on-board display and a mobile application as the local and remote user interface, and the infrastructure is composed mainly by an embedded Zigbee module that allows data to be sent by a local gateway, and an Internet Wi-Fi router to make data available for the "EasyWash service" application.

The research questions are: which is the global impact on sustainability of the new PSS solution? How do they change for different use scenarios? Which are the achievable benefits in respect with the traditional product? How are they distributed within the VME? And how to optimize the sustainability for each ecosystem actor?

\subsection{The Virtual Manufacturing Enterprise}

The case study considers a real VME, which is actually working together for the development of some research projects. The VME members and their correlation with the PSS lifecycle phases are briefly described. Indesit Company: it is the product (washing machine) manufacturing company and it participates by involving different departments (R\&D, marketing, service, IT). Its role is crucial in product manufacturing and service implementation, and it also participates in PSS creation, commercialization and delivery. Bticino: it is a leader in electrical installations distribution and it supplies high innovation electronics for the implementation of the "EasyWash service". It is involved in product manufacturing and in service implementation by providing the necessary electronic components and sensors. Softeco: it is an Italian software company that cares about the software infrastructure of the "EasyWash service" and the development of its application and user interfaces. It is mainly involved in the PSS creation. Energy Utility (reserved): it provides a customized service for the "EasyWash service" energy consumption. It is involved in the PSS use and operation phases and it cares about the environmental and economic impacts for energy. Detergent producer (reserved): it supplies the detergent for the service use and provides marketing offers to consumers. It participates in the PSS use and operation phases. Dismantling Consortium: it cares about the PSS end-of-life and decommission. Customers: they are the main actors during the PSS use and operation phases and they charge of the service agreement costs and water consumption.

\subsection{The Use Scenarios}

The use scenarios investigate the user profiles representing different lifestyles. They differ for the average number of cycle executed in a fix time period (week): House Manager (HM) (4,3 cycles/weeks), Efficiency Seeker (ES) (5,8 cycles/week), and Delegator $(D)$ (3,9 cycles/week). Data derive from a European investigation carried out by Indesit Marketing. The service agreement is assumed as the same for each 
scenario: customers pay an annual fee (e.g. 120 euro/year) to have the "Easy Wash Service" comprehending the machine, the energy and the detergent supply, and the mobile app. So energy and detergent consumptions and costs are in charged of the VME. Contrarily, water consumption is in charge of the user as traditionally. The analyzed impact will vary according to the considered lifetime: for washing machine the average lifetime is 10 years.

\subsection{Results and Discussion}

In order to answer the research questions presented in section 4, the proposed method has been applied to each use scenario. As a result, the impacts have been separately calculated and then normalized and summed. The analysis has been repeated for the traditional product by considering different lifetimes. Table 1 shows the comparative analysis values for 10-year lifetime. Results demonstrate that PSS is globally more advantageous (lower impact) for all the points of view (environmental, economic and social) and for all the analyzed use scenarios. Benefits are almost proportional to the washing use (more intensive is the use, greater are the benefits). Subsequently, the PSS impacts have been investigated along the lifecycle and in relation to the VME members' contributions.

Table 1. Sustainability assessment of PSS and traditional product for the use scenarios

\begin{tabular}{l|c|c|c|c|c|c}
\hline \multirow{2}{*}{ 10-year lifetime } & \multicolumn{2}{|c|}{ House Manager (HM) } & \multicolumn{2}{c}{ Efficiency Seeker (ES) } & \multicolumn{2}{c}{ Delegator (D) } \\
\cline { 2 - 7 } & Product & PSS & Product & PSS & Product & PSS \\
\hline $\begin{array}{l}\text { Environmental Impact } \\
\text { LCA (Pt) }\end{array}$ & 365,96 & 339,60 & 419,20 & 382,84 & 376,60 & 350,24 \\
\hline $\begin{array}{l}\text { Economic Impact } \\
\text { LCCA (euro) }\end{array}$ & $€ 488,03$ & $€ 413,35$ & $€ 565,99$ & $€ 464,12$ & $€ 496,71$ & $€ 410,31$ \\
\hline $\begin{array}{l}\text { Social Impact } \\
\text { SLCA (QALY) }\end{array}$ & $8,9 \mathrm{E}-04$ & $7,58 \mathrm{E}-04$ & $1,21 \mathrm{E}-03$ & $1,01 \mathrm{E}-03$ & $9,41 \mathrm{E}-04$ & $8,07 \mathrm{E}-04$ \\
\hline $\begin{array}{l}\text { Sustainability Assessment } \\
\text { SA (euro) }\end{array}$ & $€ \mathbf{5 6 5 , 9 4}$ & $€ \mathbf{4 8 0 , 6 7}$ & $€ \mathbf{6 6 9 , 4 7}$ & $€ \mathbf{5 5 1 , 8 6}$ & $€ \mathbf{5 7 8 , 5 6}$ & $\mathbf{€ ~ 4 8 1 , 5 8}$ \\
\hline
\end{tabular}

Table 2 shows the detailed data for the House Manager scenario and a 10-year lifetime. Expressing the single impact by percentage allows highlighting the most critical phases, where the VME should work to optimize the global sustainability. Results from Table 2 reveal that the product manufacturing company has the highest environmental impact due to product manufacturing, but the economic impact is limited. Diversely, the Detergent producer has the greatest cost while the environmental impact is limited. The dismantling Consortium has negative environmental impact as it allows recycling and reusing some items. In this case the VME should work to reduce the costs associated to detergents and improve product sustainability. Analysis of the other scenarios showed that the VME impact distribution does not vary. Such an investigation can be carried put also over the years to provide an overview of the PSS advantages along the lifetime and compare different business models for the VME. Such results could be further exploit to realize a sustainable VME able to efficiently manage a specific PSS solution. It can be a new evaluation metric to be inserted in novel collaborative design systems [19]. 
Table 2. PSS impacts distribution in the VME

\begin{tabular}{|c|c|c|c|c|c|c|c|}
\hline \multicolumn{8}{|c|}{ House Manager PSS scenario 10-year lifetime } \\
\hline \multirow[t]{2}{*}{ VME } & \multirow[t]{2}{*}{ PSS lifecycle phases } & \multicolumn{2}{|c|}{$\begin{array}{c}\text { Environmental } \\
\text { Impact }\end{array}$} & \multicolumn{2}{|c|}{ Economic Impact } & \multicolumn{2}{|c|}{ Social Impact } \\
\hline & & Pt. & $\%$ & euro & $\%$ & QALY & $\%$ \\
\hline \multirow{4}{*}{$\begin{array}{l}\text { Indesit } \\
\text { Company }\end{array}$} & PRODUCT manufacturing & 230,52 & $67,7 \%$ & $€ 25,79$ & $6,3 \%$ & $1,33 \mathrm{E}-04$ & $17,54 \%$ \\
\hline & SERVICE implementation & 6,13 & $1,8 \%$ & $€ 23,45$ & $5,7 \%$ & $9,42 \mathrm{E}-05$ & $12,43 \%$ \\
\hline & PSS creation & 14,77 & $4,3 \%$ & $€ 11,72$ & $2,8 \%$ & 4 E-06 & $0,53 \%$ \\
\hline & PSS comm. \& delivery & 0,23 & $0,2 \%$ & $€ 111,37$ & $26,9 \%$ & - & \\
\hline \multirow{2}{*}{ Bticino } & PRODUCT manufacturing & 18,66 & $5,5 \%$ & $€ 7,03$ & $1,7 \%$ & $1,09 \mathrm{E}-04$ & $14,38 \%$ \\
\hline & SERVICE implementation & 28,87 & $8,5 \%$ & $€ 5,86$ & $1,4 \%$ & & \\
\hline Softeco & PSS creation & 23,35 & $6,8 \%$ & $€ 11,72$ & $2,8 \%$ & $4,38 \mathrm{E}-05$ & $5,78 \%$ \\
\hline $\begin{array}{l}\text { Energy } \\
\text { Utility }\end{array}$ & PSS use/operation & 54,95 & $16,2 \%$ & $€ 29,31$ & $7,1 \%$ & 3,35 E-04 & $44,19 \%$ \\
\hline $\begin{array}{l}\text { Detergent } \\
\text { producer }\end{array}$ & PSS use/operation & 48,65 & $14,3 \%$ & $€ 170,92$ & $41,3 \%$ & $2,24 \mathrm{E}-04$ & $29,55 \%$ \\
\hline Consumer & PSS use/operation & 2,99 & $1 \%$ & $€ 15,47$ & $3,7 \%$ & $2,11 \mathrm{E}-05$ & $2,78 \%$ \\
\hline $\begin{array}{l}\text { Dismantling } \\
\text { Consortium }\end{array}$ & PSS EoL/decommission & $-89,52$ & $-26,3 \%$ & $€ 0,70$ & $0,3 \%$ & - 2,06 E-04 & $\begin{array}{c}-27,17 \\
\%\end{array}$ \\
\hline \multicolumn{2}{|c|}{ TOTAL IMPACT } & 339,60 & $100 \%$ & $€ 413,35$ & $100 \%$ & 7,58 E-04 & $100 \%$ \\
\hline
\end{tabular}

\section{Conclusions}

The paper proposes a methodology to support PSS ideation and VME configuration by assessing PSS sustainability. It allows investigating the impacts of PSS as well as products along the lifecycle phases with respect to three impact categories: environment, economics and social wellbeing. Its validity is demonstrated by an industrial case study proposing an "EasyWash service" in comparison with traditional washing machine selling and use. The impacts are investigated in relation to the involved VME to identify the necessary optimization to improve the global sustainability. The method can be extended to other services and application scenario.

\section{References}

1. Goedkoop, M.J., Van Halen, C.J.G., Riele, H.R.M., Rommens, P.J.M.: Product-Service Systems. In: Ecological and Economic Basic. PWC, The Hague (1999)

2. Peruzzini, M., Germani, M., Favi, C.: Shift from PLM to SLM: a method to support business requirements elicitation for service innovation. In: Proc. International Conference on Product Lifecycle Management, Montreal, Canada, pp. 1-15 (2012)

3. Peruzzini, M., Germani, M.: Investigating the Sustainability of Product and ProductService Systems in the B2C Industry. In: Meier, H. (ed.) Product-Service Integration for Sustainable Solutions. LNPE, vol. 6, pp. 421-434. Springer, Heidelberg (2013)

4. Thoben, K.D., Jagdev, H., Eschenbaecher, J.: Extended Products: Evolving Traditional Product Concepts. In: Proc. 7th International Conference on Concurrent Enterprising, Bremen (2001)

5. SUSPRONET final report, http: / /www. suspronet.org/

6. Adams, W.M.: The Future of Sustainability: Re-thinking Environment and Development in the Twenty-first Century. Report of the IUCN Renowned Thinkers Meeting (2006) 
7. Baines, T.S., Lightfoot, H., Evans, S., Neely, A., Greenough, R., Peppard, J., Roy, R., Shehab, E., Braganza, A., Tiwari, A., Alcock, J.R., Angus, J.P., Bastl, M., Cousens, A., Irving, P., Johnson, M., Kingston, J., Lockett, H., Martinez, V., Michele, P., Tranfield, D., Walton, I.M., Wilson, H.: State of the art in Product-Service System. Journal of Engineering Manufacture 221, 1543-1552 (2007)

8. Favi, C., Peruzzini, M., Germani, M.: A lifecycle design approach to analyse the ecosustainability of industrial products and product-service systems. In: Marjanovic, Storga, Pavkovic, Bojcetic (eds.) Proc. of International Design Conference DESIGN 2012, pp. 879-888 (2012)

9. Stahel, W.: The Utilization-Focused Service Economy, Resource Efficiency and ProductLife Extension. In: Allenby, B., Richard, D. (eds.) The Greening of Industrial Ecosystem, pp. 178-190. National Academy Press, Washington, DC (1994)

10. Jeswiet, J.: A definition for life cycle engineering. In: Proc. 36th International Seminar on Manufacturing Systems, Saarbrucken Germany (2003)

11. Curran, M.A.: Environmental Life Cycle Assessment. McGraw-Hill (1996)

12. ISO 14040:2006 Environmental Management - Life Cycle Assessment - Principles and Framework (2006)

13. Woodward, D.G.: Life cycle costing - theory, information acquisition and application. Int. J. Project Management 15(6), 335-344 (1997)

14. Weidema, B.: The integration of economic and social aspects in life cycle impact assessment. Int. J. Life Cycle Assess 11(1), 89-96 (2006)

15. Byrne, J.A., Brandt, R., Port, O.: The virtual corporation. The company of the future will be ultimate in adaptability. Business Week 36, 36-40 (1993)

16. Nishioka, Y., Kamio, Y., Kawashima, K., Fukuda, Y.: A Booking Type Production System as a Collaboration Method for Virtual Enterprises, Global Engineering. In: Manufacturing and Enterprise Networks, pp. 164-172. Kluwer Academic Publishers (2001)

17. Germani, M., Mengoni, M., Peruzzini, M.: A benchmarking method to investigate codesign virtual environments for enhancing industrial collaboration. In: Proc. ASME World Conference on Innovative VR 2010 (WINVR), Ames, IOWA (USA), May 12-14 (2010)

18. Mengoni, M., Germani, M., Peruzzini, M., Mandolini, M.: A novel knowledge-based approach to support virtual teamwork in collaborative design. In: Virtual Engineering, International Conference on Tools and Methods of Competitive Engineering (TMCE 2010), Ancona, Italy, April 12-16, vol. 1, pp. 461-474 (2010)

19. Germani, M., Mandolini, M., Mengoni, M., Peruzzini, M.: Collaborative design system for supporting dynamic virtual enterprises. In: Camarinha-Matos, L.M., Boucher, X., Afsarmanesh, H. (eds.) PRO-VE 2010. IFIP AICT, vol. 336, pp. 577-584. Springer, Heidelberg (2010) 